\title{
The natural and unnatural history of the systemic right ventricle in adult survivors
}

\author{
Richard Dobson, MBChB, MRCP, Mark Danton, MD, FRCS, Walker Nicola, PhD, MRCP, and \\ Walker Hamish, MD, MRCP
}

Objective: The study objective was to evaluate long-term trends in morbidity and mortality in a national cohort of adult patients with a systemic right ventricle due to the atrial switch for transposition of the great arteries or congenitally corrected transposition of the great arteries.

\begin{abstract}
Methods: We performed a retrospective cohort study from a baseline of 18 years, including life table and Kaplan-Meier analysis for probability of death/transplant, arrhythmia, surgical or percutaneous intervention,
\end{abstract} and permanent pacemaker insertion.

\begin{abstract}
Results: A total of 97 adults with transposition of the great arteries-atrial switch (Mustard procedure in 80/Senning procedure in 17) and 32 adults with congenitally corrected transposition of the great arteries survived. The median ages at latest follow-up were 29 and 34 years, respectively. At 40 years of follow-up, freedom from death or transplant was 0.90 for those with transposition of the great arteries-atrial switch and 0.84 for those with congenitally corrected transposition of the great arteries $(P=.833)$. Freedom from arrhythmia at 40 years of follow-up was 0.51 for those with transposition of the great arteries-atrial switch and 0.93 for those with congenitally corrected transposition of the great arteries $(P=.007)$. Freedom from intervention at 40 years of follow-up was 0.33 for those with transposition of the great arteries-atrial switch after initial repair and 0.53 for those with congenitally corrected transposition of the great arteries $(P=.938)$. Freedom from pacemaker insertion at 40 years of follow-up was 0.77 for those with transposition of the great arteries-atrial switch and 0.62 for those with congenitally corrected transposition of the great arteries $(P=.161)$.
\end{abstract}

Conclusions: Those patients who survive to adulthood with a systemic right ventricle experience low mortality and good functional status up to 40 years of age. However, there is a substantial burden of atrial tachyarrhythmia, and this occurs significantly earlier in those with transposition of the great arteries-atrial switch. Management of atrial tachyarrhythmia, along with systemic right ventricular dysfunction and systemic atrioventricular valve regurgitation, is likely to be the major challenge for this group of patients over the next decade. ( $\mathrm{J}$ Thorac Cardiovasc Surg 2013;145:1493-503)

The morphologic right ventricle (RV) supports the systemic circulation in those individuals with congenitally corrected transposition of the great arteries (ccTGA) and those who have survived atrial switch surgery (the Mustard or Senning procedure) for complete transposition of the great arteries (TGA). Although atrial switch is no longer the gold standard for management of TGA, having been superseded by the arterial switch operation in the late 1980s, many adult patients with TGA will have undergone the older procedure.

\footnotetext{
From the Scottish Adult Congenital and Cardiac Service, Golden Jubilee National Hospital, Beardmore Road, Clydebank, Dunbartonshire, United Kingdom.

Disclosures: R. D. is currently employed in a post that has partial funding from Actelion. W. H. has received educational grants and consultancy fees from Actelion. The other authors have nothing to disclose with regard to commercial support.

Read at the 92nd Annual Meeting of The American Association for Thoracic Surgery, San Francisco, California, April 28-May 2, 2012.

Received for publication April 7, 2012; revisions received Jan 12, 2013; accepted for publication Feb 13, 2013; available ahead of print March 13, 2013.

Address for reprints: Richard Dobson, MBChB, MRCP, Scottish Adult Congenital and Cardiac Service, Golden Jubilee National Hospital, Beardmore Rd, Clydebank, Dunbartonshire, UK G81 4DY (E-mail: richard.dobson@nhs.net). $0022-5223 / \$ 36.00$

Copyright (c) 2013 by The American Association for Thoracic Surgery http://dx.doi.org/10.1016/j.jtcvs.2013.02.030
}

Patients with either diagnosis are at risk of a host of complications associated with the systemic RV (SRV), including premature heart failure, regurgitation through the systemic atrioventricular (AV) valve, AV nodal block and a need for permanent pacing, tachyarrhythmia, and sudden cardiac death.

The long-term history of patients with an SRV still needs to be clearly defined. Most of the cohort studies of patients after atrial switch focus on establishing which of the Mustard and Senning procedures was the best procedure to use, and the majority provide followup to only 20 years. Patients with ccTGA are the subject of only a handful of cohort studies. Our aim was to establish the natural history of the SRV in both conditions and provide a benchmark to which other treatment approaches for the SRV (eg, placing the morphologic left ventricle $[\mathrm{LV}]$ in the systemic circulation) can be compared.

We focused on the group of patients who have survived to at least the age of 18 years, because although this group of patients is of great interest to clinicians engaged in provision of an adult congenital heart disease service, to our 


$$
\begin{aligned}
& \text { Abbreviations and Acronyms } \\
& \begin{aligned}
\mathrm{AV} & =\text { atrioventricular } \\
\text { ccTGA } & =\text { congenitally corrected transposition of } \\
& \text { the great arteries } \\
\mathrm{LV} & =\text { left ventricle } \\
\mathrm{MRI} & =\text { magnetic resonance imaging } \\
\mathrm{PA} & =\text { pulmonary artery } \\
\mathrm{RV} & =\text { right ventricle } \\
\mathrm{SRV} & =\text { systemic right ventricle } \\
\mathrm{TGA} & =\text { transposition of the great arteries } \\
\mathrm{TR} & =\text { tricuspid regurgitation } \\
\mathrm{VSD} & =\text { ventricular septal defect }
\end{aligned}
\end{aligned}
$$

assessment of ventricular function, and we believe the values obtained from these data provide an accurate cross-sectional assessment of the cohort at the time of data collection.

Data were described as frequencies, means and standard error, and medians and interquartile range. Means were compared with the independent samples $t$ test, and medians were compared with the independent samples median test. Chi-square test using linear-by-linear association was used to assess the relationship between severity of TR and severity of SRV impairment.

Cumulative probability of survival was estimated using the Kaplan-Meier and life table method, and differences between groups were evaluated via the log-rank test. We performed analysis for survival from death or transplant, atrial tachyarrhythmia, surgical intervention after baseline, and pacemaker therapy.

Cox proportional hazards models were used to identify predictors for death or cardiac transplant. All analyses were performed using PASW Statistics v18.0.3 (IBM corporation, New York, NY).

knowledge there are no studies that assess the prognosis for these survivors.

\section{MATERIALS AND METHODS}

We performed a retrospective cohort study, with approval from the regional research ethics committee. We identified 204 patients with TGA-atrial switch or ccTGA (excluding those who had undergone single-ventricle palliation) who had attended the national pediatric or adult congenital cardiac services for Scotland. From this group of patients, we focused on the subset of adult patients (aged at least 18 years) who had an SRV. This resulted in a study population of 129 individuals. Dropout was due to patient death or transplant before the age of 18 years ( 31 patients), conversion to a systemic LV before the age of 18 years (5 patients), loss of follow-up (16 patients), or age less than 18 years at the time of data collection (23 patients).

Data were collected and anonymized for each individual from our electronic database and hospital case notes between January 2011 and 2012. Patient-specific timelines allowed calculation of survival curves for mortality, atrial arrhythmia, surgical or catheter intervention, and pacemaker insertion. Follow-up was from the age of 18 years. Patients were censored at the time of their last clinic review, date of death, date of cardiac transplant, or date of surgery to restore the morphologic LV to the systemic circulation (a Senning-Rastelli or arterial switch operation).

During long-term follow-up, patients underwent regular clinical review that included establishment of New York Heart Association status and ascertainment of occurrence of cardiovascular events, such as arrhythmia, hospital admission, and intervention.

Tachyarrhythmia was defined as any supraventricular or ventricular tachyarrhythmia captured on ambulatory or 12-lead electrocardiograph recording that was clinically significant (ie, caused symptoms or required treatment). We excluded cases in which tachyarrhythmia occurred exclusively within 30 days of cardiac surgery. Reintervention was defined as any cardiac surgical or percutaneous cardiac procedure occurring after baseline. Pacemaker insertion was defined as any permanent epicardial or endocardial pacemaker, and included those with cardiac resynchronization therapy.

Regular imaging with transthoracic echocardiography and, when no contraindications existed, cardiac magnetic resonance imaging (MRI) was performed (Table 1). This was used to establish the degree of tricuspid regurgitation (TR) and SRV dysfunction. A total of 50 patients underwent formal cardiopulmonary exercise testing, and peak oxygen uptake (measured in $\mathrm{mL} \cdot \mathrm{kg} \cdot \mathrm{min}^{-1}$ ) was recorded if the test was maximal (Table 1). Since 2010, cardiac MRI and cardiopulmonary exercise test have been performed routinely on both groups of patients regardless of functional status or presumed need for surgery to clarify anatomy and provide more accurate

\section{RESULTS}

We first identified the 204 patients in the pediatric population (Figure 2). Patients were censored at the time of their transplant, or when they underwent surgery that restored the morphologic LV to the systemic circulation and the $\mathrm{RV}$ to the pulmonary circulation (ie, a double switch or Senning-Rastelli). Although a clear survival advantage up to 10 years was experienced by those with TGA-atrial switch, mortality between the 2 cohorts was remarkably similar after this time (log-rank $P=.657$ ). Of 133 patients with TGA-atrial switch ( 89 male, 44 female), 88 had ongoing follow-up, 23 died, 19 were lost to follow-up, 2 underwent cardiac transplantation, and 1 underwent a subsequent arterial switch procedure. Of 71 patients with ccTGA (46 male, 25 female), 49 had ongoing follow-up, 14 died, 3 were lost to follow-up, 1 underwent cardiac transplantation, 1 underwent an atrial and arterial double switch operation, and 3 underwent Senning-Rastelli repair.

The red line indicates the period from 18 years of followup and the major area of interest for this study. There were 97 adult survivors of atrial switch surgery for TGA and 32 adult survivors of ccTGA. The characteristics are outlined in Table 1.

Most of the patients undergoing atrial switch had undergone a Mustard repair, with only $17 \%$ undergoing the Senning procedure. More coexistent lesions were present in those patients with a diagnosis of ccTGA. By the end of the follow-up period, the majority of patients had good functional status, normal or only mild impairment of SRV function, and no or mild TR, with only 2 patients with ccTGA proceeding to tricuspid valve replacement and only 3 patients with severe regurgitation.

We assessed the relationship between SRV impairment and severity of TR. The 2 patients who underwent tricuspid valve replacement were excluded from the analysis. The chi-square value for linear-by-linear association between SRV impairment and severity of TR was 10.064 last review, when they died, when they received a cardiac 
TABLE 1. Baseline characteristics, morbidity, and final outcome in patients with transposition of the great arteries-atrial switch and congenitally corrected transposition of the great arteries

\begin{tabular}{|c|c|c|c|}
\hline & $\begin{array}{l}\text { TGA-atrial } \\
\text { switch }\end{array}$ & ccTGA & $P$ value \\
\hline $\mathrm{N}$ & 97 & 32 & \\
\hline Male & 64 & 20 & \\
\hline Female & 33 & 12 & \\
\hline \multicolumn{4}{|l|}{ Age (y) } \\
\hline Median (IQR) & $29(25-32)$ & $33(23-46)$ & .331 \\
\hline \multicolumn{4}{|l|}{ Follow-up from $18 \mathrm{y}$} \\
\hline Median (IQR) & $10.8(6.5-13.9)$ & $13.2(5.1-28.2)$ & .256 \\
\hline \multicolumn{4}{|l|}{$\begin{array}{l}\text { Atrial switch operation } \\
\qquad(\%)\end{array}$} \\
\hline Mustard & $80(83)$ & N/A & \\
\hline Senning & $17(17)$ & N/A & \\
\hline \multicolumn{4}{|l|}{$\begin{array}{l}\text { Coexistent congenital } \\
\text { lesions }\end{array}$} \\
\hline Dextrocardia & 0 & 7 & \\
\hline VSD & 10 & 20 & \\
\hline Pulmonary stenosis & 13 & 11 & \\
\hline Pulmonary atresia & 0 & 4 & \\
\hline Ebstein & 0 & 1 & \\
\hline Coarctation & 3 & 0 & \\
\hline \multicolumn{4}{|l|}{ Outcome } \\
\hline Ongoing follow-up & 86 & 28 & \\
\hline Lost to follow-up & 5 & 1 & \\
\hline Died & 5 & 2 & \\
\hline Transplant & 1 & 1 & \\
\hline \multicolumn{4}{|l|}{ Cause of death } \\
\hline Heart failure & 1 & 1 & \\
\hline Sudden & 3 & 1 & \\
\hline Sepsis & 1 & 0 & \\
\hline \multicolumn{4}{|l|}{ Tachyarrhythmia } \\
\hline No & 72 & 26 & \\
\hline Yes & 21 & 4 & \\
\hline \multicolumn{4}{|l|}{ Up-to-date imaging ( $\%$ ) } \\
\hline Echocardiography & $73(75)$ & $24(73)$ & \\
\hline MRI & $22(22)$ & $5(16)$ & \\
\hline \multicolumn{4}{|l|}{ SRV impairment } \\
\hline Nil & 26 & 10 & \\
\hline Mild & 32 & 13 & \\
\hline Moderate & 18 & 5 & \\
\hline Severe & 6 & 1 & \\
\hline \multicolumn{4}{|l|}{$\begin{array}{l}\text { Cardiac MRI } \\
\qquad(\text { mean } \pm \mathrm{SE})\end{array}$} \\
\hline SRV EDV & $111 \pm 8.8$ & $127 \pm 18.3$ & .442 \\
\hline SRV EF \% & $54 \pm 2.3$ & $61 \pm 2.6$ & .190 \\
\hline LVEDV & $79 \pm 6.0$ & $92 \pm 11.0$ & .337 \\
\hline LVEF \% & $60 \pm 2.6$ & $66 \pm 3.3$ & .220 \\
\hline \multicolumn{4}{|l|}{ TR } \\
\hline Nil & 42 & 2 & \\
\hline Mild & 40 & 12 & \\
\hline Moderate & 13 & 9 & \\
\hline Severe & 0 & 3 & \\
\hline Replaced & 0 & 2 & \\
\hline
\end{tabular}

TABLE 1. Continued

\begin{tabular}{|c|c|c|c|}
\hline & $\begin{array}{l}\text { TGA-atrial } \\
\text { switch }\end{array}$ & ccTGA & $P$ value \\
\hline \multicolumn{4}{|l|}{ NYHA class } \\
\hline I & 65 & 21 & \\
\hline II & 20 & 5 & \\
\hline III & 1 & 1 & \\
\hline IV & 2 & 1 & \\
\hline $\begin{array}{l}\text { No. of patients assessed } \\
\text { by CPET }(\%)\end{array}$ & $33(34)$ & $17(53)$ & \\
\hline \multicolumn{4}{|l|}{ CPET $($ mean \pm SE) } \\
\hline $\mathrm{VO}_{2} \max (\mathrm{mL} / \mathrm{kg} / \mathrm{min})$ & $25 \pm 1.2$ & $25 \pm 2.1$ & .937 \\
\hline $\begin{array}{l}\mathrm{VO}_{2} \max (\% \text { peak } \\
\text { predicted })\end{array}$ & $68.5 \pm 2.8$ & $62.4 \pm 4.3$ & .225 \\
\hline $\begin{array}{l}\text { Heart rate reserve } \\
\text { (beats } / \mathrm{min})\end{array}$ & $29 \pm 3.7$ & $35 \pm 5.9$ & .374 \\
\hline $\mathrm{VE} / \mathrm{VCO}_{2}$ & $36 \pm 1.1$ & $34 \pm 1.9$ & .196 \\
\hline $\begin{array}{l}\text { Female patients with at } \\
\text { least } 1 \text { successful } \\
\text { pregnancy }\end{array}$ & 7 & 3 & \\
\hline PA band $(\%)$ & $13(13)$ & $1(3)$ & \\
\hline Median age (IQR) & $20.6(18.0-25.8)$ & $14.2(\mathrm{~N} / \mathrm{A})$ & \\
\hline $\begin{array}{l}\text { Median follow-up (y) } \\
\text { post-PAB (IQR) }\end{array}$ & $5.8(4.3-7.2)$ & 6.4 (N/A) & \\
\hline $\begin{array}{l}\text { Median velocity } \mathrm{m} / \mathrm{s} \\
\text { (IQR) }\end{array}$ & $3.4(2.3-3.9)$ & 3.3 (N/A) & \\
\hline $\begin{array}{l}\text { Median LV:SRV } \\
\text { pressure }\end{array}$ & $0.40(0.16-0.47)$ & $0.32(\mathrm{~N} / \mathrm{A})$ & \\
\hline \multicolumn{4}{|l|}{$\begin{array}{l}\text { Baffle intervention by } \\
\text { type }\end{array}$} \\
\hline Surgery & $\begin{array}{l}12 \text { operations in } 11 \\
\text { patients }\end{array}$ & N/A & \\
\hline Catheter & $\begin{array}{l}20 \text { procedures in } 18 \\
\text { patients }\end{array}$ & N/A & \\
\hline Total* & $\begin{array}{l}32 \text { procedures in } 26 \\
\text { patients }\end{array}$ & N/A & \\
\hline \multicolumn{4}{|l|}{$\begin{array}{l}\text { Indication for baffle } \\
\text { intervention }(\%)\end{array}$} \\
\hline Baffle leak & $8(25.0)$ & N/A & \\
\hline \multicolumn{4}{|l|}{ Baffle obstruction } \\
\hline SVC limb stenosis & $10(31.3)$ & N/A & \\
\hline IVC limb stenosis & $5(15.6)$ & N/A & \\
\hline PVP stenosis & $6(18.8)$ & N/A & \\
\hline $\begin{array}{l}\text { Obstruction not } \\
\text { specified }\end{array}$ & $1(3.1)$ & N/A & \\
\hline Unknown & $1(3.1)$ & N/A & \\
\hline Pacemaker (\%) & $17(18)$ & $13(41)$ & \\
\hline CRT $(\%)$ & $3(3)$ & $1(3)$ & \\
\hline
\end{tabular}

$T G A$, Transposition of the great arteries; $c c T G A$, congenitally corrected transposition of the great arteries; $I Q R$, interquartile range; $V S D$, ventricular septal defect; $M R I$, magnetic resonance imaging; $S R V$, systemic right ventricle; $R V$, right ventricle; $S E$, standard error; $V O_{2}$ max, peak oxygen uptake in $\mathrm{mL} / \mathrm{kg} / \mathrm{min} ; E D V$, end-diastolic volume; $E F$, ejection fraction; $S R V E D V$, systemic right ventricle end-diastolic volume; $L V E D V$, left ventricle end diastolic volume; $L V E F$, left ventricular ejection fraction; $T R$, tricuspid regurgitation; NYHA, New York Heart Association; CPET, cardiopulmonary exercise test; $\mathrm{VO}_{2}$, oxygen uptake; $\mathrm{VE} / \mathrm{VCO}_{2}$, minute ventilation to carbon dioxide output ratio; $P A$, pulmonary artery; $P A B$, pulmonary artery banding; $L V$, left ventricle; $S V C$, superior vena cava; $I V C$, inferior vena cava; $P V P$, pulmonary venous pathway; $C R T$, cardiac resynchronization therapy; $N / A$, not available. *Six patients had 2 interventions each, with a total of 26 individual patients undergoing at least 1 intervention. 


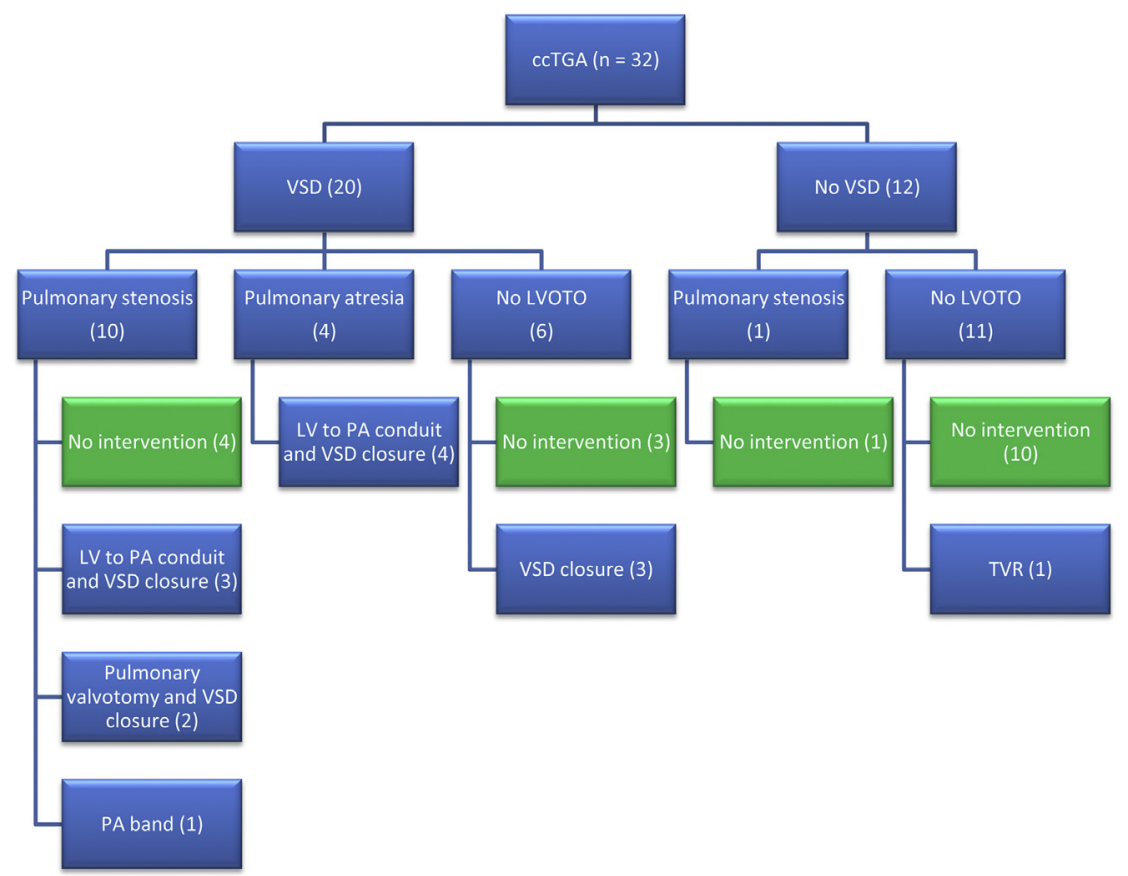

FIGURE 1. Coexistent lesions and initial surgery in 32 patients with ccTGA. $c c T G A$, Congenitally corrected transposition of the great arteries; VSD, ventricular septal defect; $L V O T O$, left ventricular outflow tract obstruction; $L V$, left ventricle; $P A$, pulmonary artery; $T V R$, tricuspid valve replacement.

$(P=.002)$, implying a statistically significant correlation between the 2 variables.

More detailed assessment of ventricular function and functional capacity was performed by means of cardiac MRI and cardiopulmonary exercise testing, because this is

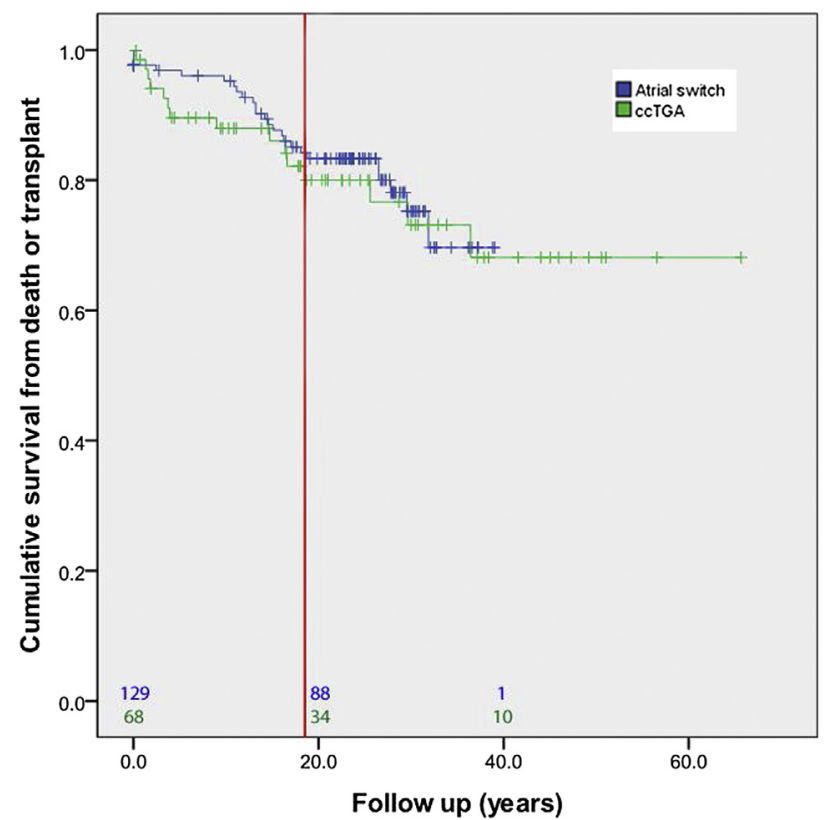

FIGURE 2. Long-term survival in 133 patients after atrial switch surgery for TGA and 71 patients with ccTGA. The red line indicates the period from 18 years of follow-up, and the major area of interest for this study. ccTGA, Congenitally corrected transposition of the great arteries. a routine form of evaluation for all eligible patients at this center with an SRV, regardless of clinical status. From cardiac MRI in 27 patients, the mean ejection fraction of the SRV was lower in those with TGA-atrial switch than in those with ccTGA $(54 \%$ vs $61 \%$ ), although this was not significant. There was no clear relationship between time from baseline and ventricular volumes or ejection fraction. Mean peak oxygen uptake for 50 patients in both groups was $25 \mathrm{~mL} / \mathrm{kg} / \mathrm{min}$. There was no statistically significant difference in peak oxygen uptake, heart rate reserve, and minute ventilation to carbon dioxide output ratio between the 2 cohorts.

Intervention was common. Baffle problems accounted for most of this in the atrial switch group, with 26 patients (26.8\% of the adult TGA-atrial switch cohort) requiring further intervention. Of this group of patients, 24 (of a possible 80) had undergone a Mustard repair, compared with 2 patients undergoing a Senning (of a possible 17). The majority of intervention was performed percutaneously, and baffle obstruction was a more frequent indication for intervention than a leak. In the majority of cases, the initial intervention was successful at treating the baffle leak or stenosis, with only 6 patients (Mustard in 5, Senning in 1) requiring more than 1 repeat intervention. In 2 patients (Senning repair), partially successful percutaneous intervention for a baffle leak was followed by definitive surgical treatment 2 years later. One patient (who underwent a Mustard repair) required 2 surgical baffle repairs, albeit 14 years apart, for obstruction of the pulmonary venous pathway. Two patients each required 2 attempts at catheter 
intervention, and the remaining 2 patients required percutaneous intervention after initial surgical revision of the baffles.

A total of 13 of 97 patients with TGA-atrial switch underwent subsequent pulmonary artery (PA) banding for treatment of SRV dysfunction, 1 of whom later died suddenly 3 years post-banding (presumed arrhythmic in cause). Upto-date imaging was not available for 1 other patient who underwent this procedure. For the remaining 11 patients, the median follow-up period was 5.8 years. The mean gradient through the PA band was $3.4 \mathrm{~m} / \mathrm{s}$. SRV function was normal or mildly impaired in 9 patients, moderately impaired in 1 patient, and severely impaired in 1 patient. There was no or mild systemic TR in 6 of 11 patients, with 4 patients having moderate regurgitation and 1 patient having severe regurgitation. None of the patients with PA banding were ever deemed suitable for a subsequent double-switch.

Other indications for reintervention in the TGA-atrial switch group were enlargement of the subpulmonary LV outflow tract, repair of aortic coarctation, and cardiac transplant. No TGA-atrial switch cases have yet been referred for tricuspid valve replacement.

In the ccTGA group, most intervention was directed at correction of underlying anatomic lesions, such as a ventricular septal defect (VSD) (Figure 1), although 1 patient with preexisting left ventricular outflow tract obstruction and a VSD required PA banding for a failing SRV, and 1 patient required tricuspid valve replacement. Both patients were doing well at their most recent follow-up. Although a number of pediatric patients have ultimately undergone a double switch or Senning-Rastelli, none of the adult survivors have.

Cumulative survival from each adverse outcome for the 129 patients who reached the age of 18 years is outlined in detail in Figure 3. The dropoff at baseline (age 18 years) reflects the number of adverse events that had occurred in individuals before the age of 18 years.

There was no significant difference in survival between patients with TGA-atrial switch and patients with ccTGA (log-rank test $P=.833$ ). Cumulative survival (including cardiac transplantation) was $0.99 \pm 0.01,0.90 \pm 0.04$, and $0.90 \pm 0.04$ at 20,30 , and 40 years post-atrial switch, respectively, and $0.97 \pm 0.03,0.91 \pm 0.06$, and $0.84 \pm$ 0.09 at 20,30 , and 40 years post-ccTGA, respectively. Although there seemed to be an abrupt decrease in survival to approximately 0.40 at more than 45 years from baseline for the TGA-atrial switch cohort, only 2 patients had been followed for this length of time; therefore, this value was not thought to be sufficiently representative of the whole cohort. There was no significant difference in survival from 18 years of follow-up between Mustard and Senning cases (log-rank test $P=.625$ ), although after 27 years of follow-up graphic trends favored those undergoing the Senning. There was no significant difference between simple and complex TGA-atrial switch $(P=.562)$. There was no significant difference in survival between simple and complex ccTGA after 18 years of follow-up (log-rank test $P=.662$ ). There was no significant difference in survival between the 14 patients in both groups who underwent PA banding and those who did not $(P=.659)$. A univariate analysis with a Cox proportional hazards model was performed to establish risk factors for death or transplant (Table 2). Severe SRV impairment at baseline was most strongly associated with risk of death or transplant, albeit with wide confidence intervals.

Patients with ccTGA demonstrate low arrhythmia burden with cumulative survival from tachyarrhythmia of 1.00 , 1.00 , and $0.93 \pm 0.07$ at 20,30 , and 40 years, respectively. This was significantly better than in those who received atrial switch, who experienced survival of $0.91 \pm 0.03$, $0.73 \pm 0.06$, and $0.54 \pm 0.14$ at 20,30 , and 40 years, respectively (log-rank test $=0.007$ ). All documented tachyarrhythmias were supraventricular: There were no instances of documented ventricular tachycardia causing symptoms or requiring treatment (although the sudden deaths that occurred may have been due to this).

Freedom from intervention at 20,30 , and 40 years of follow-up was $0.74 \pm 0.05,0.57 \pm 0.06$, and $0.33 \pm 0.08$ for TGA-atrial switch, respectively, and $0.57 \pm 0.09,0.53$ \pm 0.10 , and $0.53 \pm 0.10$ for ccTGA, respectively (log-rank test $P=.938$ ).

There was no significant difference between the 2 groups for cumulative survival from pacemaker insertion (log-rank test $P=.161$ ), although graphic trends favor the TGA-atrial switch group. Freedom from pacemaker insertion at 20,30, and 40 years of follow-up was $0.87 \pm 0.04,0.82 \pm 0.04$, and $0.77 \pm 0.06$ for TGA-atrial switch, respectively, and $0.79 \pm$ $0.08,0.69 \pm 0.09$, and $0.62 \pm 0.11$ for ccTGA, respectively.

\section{DISCUSSION \\ Mortality}

Overall mortality to 40 years is low in both cohorts, with the cumulative probability of survival estimated at $90 \%$ survival after atrial switch and $84 \%$ after ccTGA. Of the 7 deaths after 18 years of follow-up, 4 were sudden and 2 were secondary to heart failure (1 patient with ccTGA died after referral for cardiac transplant assessment). This is similar to other studies. Sudden death and heart failure accounted for the majority of late deaths in 2 large retrospective studies of a combined total of approximately 700 atrial switch cases ${ }^{1,2}$ and in a large retrospective study of survivors of surgery for ccTGA. ${ }^{3}$ Therefore, strategies to identify those at risk of sudden cardiac death and to manage systemic RV dysfunction will be crucial to improve outcomes in these patients.

Direct comparison between our cohort of adult survivors and the larger cohort studies of SRV is difficult because most studies include early postoperative and pediatric 

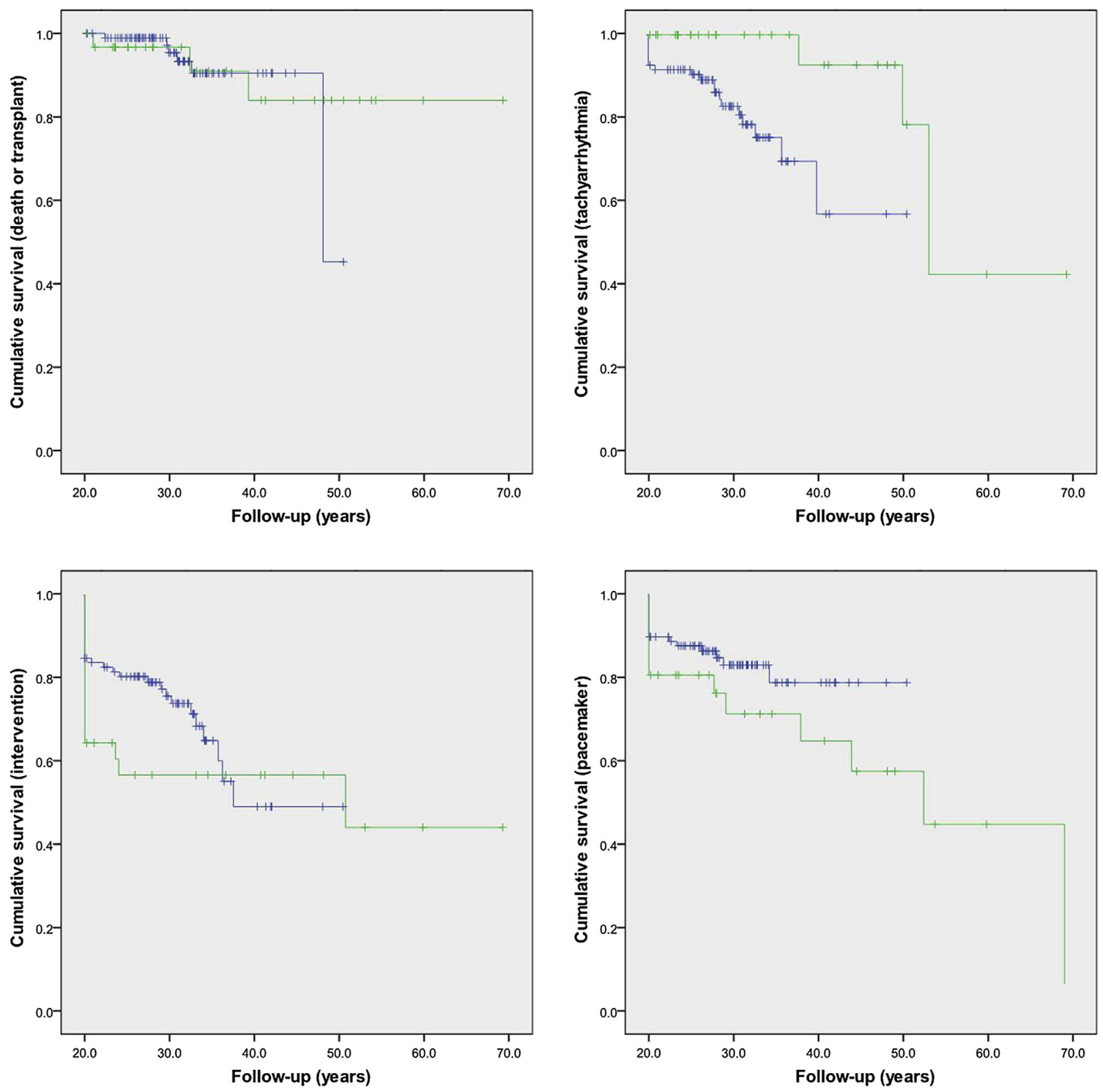

$\square$ Atrial switch $\square$ ccTGA

FIGURE 3. Mortality and morbidity in 129 adult survivors of ccTGA and atrial switch surgery for TGA. $c c T G A$, Congenitally corrected transposition of the great arteries.

deaths. We therefore included our pediatric data, and with this cumulative mortality was broadly similar (Table 3 ). It remains to be seen whether the adaptation of an early aggressive strategy for patients with ccTGA, by which the morphologic LV is connected to the systemic circulation, results in improved survival into adulthood. However, Brawn ${ }^{4}$ reports survival of $90 \%$ at up to 9 years in a cohort of 56 patients with ccTGA who underwent both types of double switch (atrial and arterial switch, and Senning-Rastelli), with an early mortality of $5.6 \% .{ }^{4}$ Ly and colleagues ${ }^{5}$ reported $100 \%$ survival at 60 months in 20 patients with complex ccTGA who underwent the Senning-Rastelli procedure. Shin'oka and colleagues ${ }^{6}$ reported $74.5 \%$ survival at 15 years in 15 patients undergoing atrial-arterial switch and $80 \%$ survival at 16 years in 69 patients undergoing the Senning-Rastelli procedure. Poorer survival was reported in the Senning-Rastelli group compared with the atrial-arterial switch group in another study with data up to 10 years of 65 patients undergoing anatomic repair. ${ }^{7}$ However, this is in contrast to a 2006 meta-analysis of 
TABLE 2. Hazard ratios for death or cardiac transplant in adult survivors with a systemic right ventricle

\begin{tabular}{lccc}
\hline \multicolumn{1}{c}{ Variable } & HR & $\boldsymbol{P}$ value & \multicolumn{1}{c}{$\mathbf{9 5 \%}$ CI } \\
\hline Male & 2.286 & .303 & $0.474-11.033$ \\
Initial VSD & 2.370 & .208 & $0.619-9.081$ \\
Initial BT shunt & 1.537 & .692 & $0.183-12.89$ \\
Tachyarrhythmia & 0.046 & .717 & $0-\infty$ \\
Pacemaker & 2.349 & .290 & $0.483-11.417$ \\
Severe TR (or valve replacement) & 3.064 & .305 & $0.360-26.072$ \\
Severe SRV impairment & 12.092 & .002 & $2.424-60.309$ \\
PA band & 1.606 & .662 & $0.191-13.484$ \\
\hline
\end{tabular}

$H R$, Hazard ratio; $C I$, confidence interval; $V S D$, ventricular septal defect; $B T$, Blalock-Taussig; $T R$, tricuspid regurgitation; $S R V$, systemic right ventricle.

124 patients undergoing anatomic repair for ccTGA in which the Senning-Rastelli procedure conferred a survival benefit at least for in-hospital mortality; however, there were no data regarding longer-term outcomes. ${ }^{8}$ Although these results are clearly encouraging, the prognosis to adulthood and beyond remains to be established.

\section{Morbidity}

Tachyarrhythmia. Atrial tachyarrhythmia was common in patients with an SRV. However, it occurred significantly earlier in survivors of atrial switch surgery $(P=.007)$. This may be due to the extensive atrial scar tissue and potential for macro-reentry circuits. The relatively high prevalence of arrhythmia in both cohorts at 40 years is cause for concern, because its management is extremely challenging even for experienced electrophysiologic physicians.

Systemic right ventricle impairment and tricuspid regurgitation. At the time this study was performed, the majority of patients in both cohorts exhibited insignificant or mild SRV impairment and TR. However, severe SRV impairment was a significant risk factor for death, and management is controversial. We confirmed a clear correlation between severity of SRV impairment and severity of TR, in keeping with the published literature. ${ }^{9,10}$ Cardiac MRI data suggested that overall mean SRV function for the group was good in ccTGA cases, with an SRV ejection fraction of $61 \%$, and only mildly impaired in atrial switch cases, with an SRV ejection fraction of $54 \%(P=.190)$. Of note, mean SRV end-diastolic volume was slightly higher in the ccTGA cases; however, the difference was not statistically significant.

Approaches to management of SRV failure are controversial. Early intervention for a regurgitant systemic tricuspid valve has been advocated in view of its correlation with SRV failure. However, results are poor in patients who have preexisting SRV impairment; therefore, this is a prophylactic strategy rather than an option for patients who already have a failing SRV. Furthermore, long-term prognostic data are lacking, and there are no large-scale case-control studies. ${ }^{10-12}$ Generally, tricuspid valve replacement rather than repair is advocated if the RV is planned to remain in the systemic circulation. ${ }^{10,13}$

The atrial-arterial double switch or Senning-Rastelli procedures, if performed early enough in a center with sufficient expertise, eliminate the problem of SRV dysfunction and TR. However, results are unfavorable in adult patients. ${ }^{4,14,15}$ Furthermore, there is a risk of a range of new complications, including dysfunction of the newly systemic LV and insufficiency through the neoaortic valve (in the case of atrial-arterial double switch). ${ }^{4}$

The process of training the LV through the placement of a PA band is used as a treatment in its own right, because higher LV pressures avoid septal dyskinesis exacerbating SRV impairment, and in theory helps to prevent tricuspid annular dilatation, thus lessening the severity of TR. In the small subcohort of our group of patients undergoing PA banding, most maintained normal or only mildly impaired SRV function. However, there was no overall

TABLE 3. Reported long-term survival for 1282 patients after atrial switch surgery and 488 patients with congenitally corrected transposition of the great arteries

\begin{tabular}{|c|c|c|c|c|c|c|c|}
\hline \multirow[b]{2}{*}{ Author } & \multirow[b]{2}{*}{ Population } & \multirow[b]{2}{*}{ Year } & \multirow[b]{2}{*}{$\mathbf{N}$} & \multicolumn{4}{|c|}{ Cumulative probability of death } \\
\hline & & & & $10 y$ & $20 y$ & $30 y$ & $40 y$ \\
\hline \multicolumn{8}{|l|}{ TGA-atrial switch } \\
\hline Dobson et al & Mustard and Senning (pediatric data) & 2012 & 133 & 0.96 & 0.83 & 0.78 & 0.68 \\
\hline Lange et $\mathrm{al}^{1}$ & Mustard only & 2006 & 395 & \multicolumn{4}{|c|}{0.86 at $25 \mathrm{y}$} \\
\hline Moons et $\mathrm{al}^{2}$ & Mustard and Senning & 2004 & 283 & 0.92 & 0.87 & 0.79 & \\
\hline Sarkar et $\mathrm{al}^{30}$ & Mustard and Senning & 1999 & 358 & $0.82 *$ & & & \\
\hline & & & & $0.94 \dagger$ & & & \\
\hline Wilson et $\mathrm{al}^{31}$ & Mustard only & 1998 & 113 & 0.90 & 0.80 & & \\
\hline \multicolumn{8}{|l|}{ ccTGA } \\
\hline Dobson et al & ccTGA (operated and unoperated) & 2012 & 71 & 0.87 & 0.79 & 0.77 & 0.67 \\
\hline Lim et $\mathrm{al}^{3}$ & ccTGA (123 physiologic and 44 anatomic repair) & 2010 & 167 & 0.8 & 0.83 & & \\
\hline Hraska et $\mathrm{al}^{32}$ & ccTGA (operated and unoperated) & 2005 & 123 & 0.72 & 0.59 & & \\
\hline Yeh et $\mathrm{al}^{33}$ & ccTGA (physiologic and 9 anatomic repair) & 1999 & 127 & & 0.80 & & 0.66 \\
\hline
\end{tabular}

$T G A$, Transposition of the great arteries; $c c T G A$, congenitally corrected transposition of the great arteries. *Mustard. $\dagger$ Senning. 
improvement in the degree of TR when pre-PA band data existed. This is confirmed by 2 relatively large studies of 39 and 20 patients, ${ }^{16,17}$ respectively, although some older, smaller trials suggest a modest beneficial effect on TR. ${ }^{13,18,19}$ The biggest problem with PA banding seems to be the development of dysfunction of the subpulmonary LV. ${ }^{16,19}$

There is only modest evidence for the efficacy of cardiac resynchronization therapy, and again the main problem seems to be the development of LV dysfunction. ${ }^{20,21}$ Cardiac transplantation is effective; however, there is the problem of limited donor organ availability in many parts of the world and the additional risk conferred by the complexity of abnormal anatomy and previous surgical intervention.

\section{Functional Data}

In keeping with the other cohort studies described previously, patients with atrial switch and patients with ccTGA continue to enjoy good functional status. Approximately $98 \%$ of patients with atrial switch for whom data were available (85/87) and $93 \%$ of patients with ccTGA (26/ 28) were in New York Heart Association class I or II. Median follow-up was to 29 and 33 years of age, respectively.

Formal cardiopulmonary exercise testing demonstrated reduced maximum oxygen uptake compared with peak predicted, with a mean peak oxygen uptake of $25 \mathrm{~mL} / \mathrm{kg} / \mathrm{min}$ for both atrial switch and ccTGA cases. This is in keeping with previous studies assessing exercise performance in patients with an SRV. ${ }^{22,23}$ We also demonstrated evidence of an abnormally high heart rate reserve and increased minute ventilation to carbon dioxide output ratio, again in keeping with previous work. ${ }^{24-26}$

\section{Reintervention}

There was relatively high attrition in both cohorts, with cumulative probability of freedom from reintervention of $57 \%$ in atrial switch cases and 53\% in ccTGA cases at 30 years.

In the TGA-atrial switch cohort, the relatively high rate of baffle reintervention may be explained by the fact that most patients had undergone a Mustard repair, and this technique was associated with a higher incidence of baffle obstruction than the Senning repair in an earlier meta-analysis. ${ }^{27}$ There was only 1 cardiac transplant. There have been no systemic AV valve replacements. Although 1 arterial switch procedure was performed in a patient who had previously undergone atrial switch, this was performed at the age of 8 years, and therefore before at least 18 years of follow-up had elapsed.

In the ccTGA cohort, physiologic repair of coexistent cardiac lesions accounted for most intervention. Most surgery was performed during childhood, with intervention after 18 years far less common than intervention before
18 years. The only surgery performed after 18 years of age was 1 tricuspid valve replacement and 1 late physiologic repair involving VSD closure and relief of left ventricular outflow tract obstruction via pulmonary valvotomy.

Systemic AV (tricuspid) valve replacement in patients with an SRV is controversial. Some centers advocate early replacement of an incompetent systemic AV valve because of the relationship between SRV impairment and systemic atrioventricular valve regurgitation. A double switch strategy, with a subsequent arterial switch operation, also is controversial. ${ }^{28}$

\section{Pacemaker Therapy}

There was no significant difference between the 2 cohorts for survival from pacemaker insertion, and this was a particularly common problem in the ccTGA cohort. Use of cardiac resynchronization therapy was low, presumably reflecting the lack of evidence to support its use. Of note, there were no automatic implantable cardioverter defibrillator insertions. Although there is a high risk of sudden cardiac death, there are no established guidelines for formal risk assessment, and automatic implantable cardioverter defibrillator insertion in patients with an SRV is based on a "common sense" approach extrapolated from studies in other populations. ${ }^{29}$

\section{Study Limitations}

As with all retrospective studies, our study is limited by those patients lost to follow-up both before and after the age of 18 years, although these numbers were relatively small. Another group of patients missing from the analysis are those with asymptomatic uncomplicated ccTGA, who have yet to present to medical services or are not recognized as having cardiac anatomy consistent with ccTGA. However, on the basis of our own experience, few patients with ccTGA present after the age of 18 years. Furthermore, all longitudinal cohort studies of ccTGA will have the same problem.

Functional data regarding ventricular function as assessed by cardiac MRI are lacking for a relatively large number of patients, and in many cases this is unavoidable because of the presence of a cardiac rhythm device. Furthermore, our service has yet to fully assess the cohort of patients with SRV by means of a cardiopulmonary exercise test, and the sickest patients are typically too unwell to allow determination of peak exercise capacity by this method.

\section{CONCLUSIONS}

Overall mortality is low at up to 40 years of follow-up in adult survivors of atrial switch surgery for TGA or ccTGA. Furthermore, mortality is remarkably similar between the 2 cohorts. This suggests that for the majority of patients, it is actually the SRV itself, rather than the nature of any prior surgery, that determines true long-term prognosis. SRV 
dysfunction increases the overall hazard for death or transplant, and most deaths are sudden or due to heart failure.

Morbidity is substantial, with a high incidence of tachyarrhythmia, surgical or catheter intervention, and pacemaker insertion. Tachyarrhythmia is a particular problem for TGA-atrial switch cases because it occurs significantly earlier than in ccTGA cases. However, moderate to severe SRV dysfunction, TR, and functional impairment are relatively rare up to 40 years. Risk stratification for sudden cardiac death and the identification of suitable strategies to manage SRV impairment will be key to improving survival in the future. In view of the high burden of SRV impairment, an early aggressive strategy aimed at anatomic repair may be warranted in the patients with ccTGA who require corrective surgery for coexistent lesions. For the asymptomatic patient with uncomplicated ccTGA, there is insufficient adult follow-up data to comment on whether an anatomic repair strategy is better than conservative management.

The authors thank Dr David Young, Department of Statistics and Modeling Science, University of Strathclyde, for advice on statistical methodology and interpretation.

\section{References}

1. Lange R, Horer J, Kostolny M, Cleuziou J, Vogt M, Busch R, et al. Presence of a ventricular septal defect and the Mustard operation are risk factors for late mortality after the atrial switch operation: thirty years of follow-up in 417 patients at a single center. Circulation. 2006;114:1905-13.

2. Moons P, Gewillig M, Sluysmans T, Verhaaren H, Viart P, Massin M, et al. Long term outcome up to 30 years after the Mustard or Senning operation: a nationwide multicentre study in Belgium. Heart. 2004;90:307-13.

3. Lim HG, Lee JR, Kim YJ, Park YH, Jun TG, Kim WH, et al. Outcomes of biventricular repair for congenitally corrected transposition of the great arteries. Ann Thorac Surg. 2010;89:159-67.

4. Brawn WJ. The double switch for atrioventricular discordance. Semin Thorac Cardiovasc Surg Pediatr Card Surg Annu. 2005;51-6. Review.

5. Ly M, Belli E, Leobon B, Kortas C, Grollmuss OE, Piot D, et al. Results of the double switch operation for congenitally corrected transposition of the great arteries. Eur J Cardiothoracic Surg. 2009;35:879-84.

6. Shin'oka T, Kurosawa H, Imai Y, Aoki M, Ishiyama M, Sakamoto T, et al. Outcomes of definitive surgical repair for congenitally corrected transposition of the great arteries or double outlet right ventricle with discordant atrioventricular connections: risk analyses in 189 patients. J Thorac Cardiovasc Surg. 2007;133: 1318-28.

7. Gaies MG, Goldberg CS, Ohye RG, Devaney EJ, Hirsch JC, Bove EL. Early and intermediate outcome after anatomic repair of congenitally corrected transposition of the great arteries. Ann Thorac Surg. 2009;88:1952-60.

8. Alghamdi AA, McCrindle BW, Van Arsdell GS. Physiologic versus anatomic repair of congenitally corrected transposition of the great arteries: meta-analysis of individual patient data. Ann Thorac Surg. 2006;81:1529-35.

9. Warnes CA. Transposition of the great arteries. Circulation. 2006;114:2699-709.

10. Scherptong RW, Vliegen HW, Winter MM, Holman ER, Mulder BJ, van der Wall EE, et al. Tricuspid valve surgery in adults with a dysfunctional systemic right ventricle: repair or replace? Circulation. 2009;119:1467-72.

11. Mongeon FP, Connolly HM, Dearani JA, Li Z, Warnes CA. Congenitally corrected transposition of the great arteries ventricular function at the time of systemic atrioventricular valve replacement predicts long-term ventricular function. J Am Coll Cardiol. 2011;57:2008-17.

12. van Son JAM, Danielson GK, Huhta JC, Warnes CA, Edwards WD, Schaff HV, et al. Late results of systemic atrioventricular valve replacement in corrected transposition. J Thorac Cardiovasc Surg. 1995;109:642-53.

13. Acar P, Sidi D, Bonnet D, Aggoun Y, Bonhoeffer P, Kachaner J. Maintaining tricuspid valve competence in double discordance: a challenge for the paediatric cardiologist. Heart. 1998;80:479-83.
14. Benzaquen BS, Webb GD, Colman JM, Therrien J. Arterial switch operation after Mustard procedures in adult patients with transposition of the great arteries: is it time to revise our strategy? Am Heart J. 2004;147:E8.

15. Metton O, Gaudin R, Ou P, Gerelli S, Mussa S, Sidi D, et al. Early prophylactic pulmonary artery banding in isolated congenitally corrected transposition of the great arteries. Eur J Cardiothorac Surg. 2010;38:728-34.

16. Winlaw DS, McGuirk SP, Balmer C, Langley SM, Griselli M, Stumper O, et al Intention-to-treat analysis of pulmonary artery banding in conditions with a morphological right ventricle in the systemic circulation with a view to anatomic biventricular repair. Circulation. 2005;111:405-11.

17. Cools B, Brown SC, Louw J, Heying R, Meyns B, Gewillig M. Pulmonary artery banding as 'open end' palliation of systemic right ventricles: an interim analysis. Eur J Cardiothorac Surg. 2012;41:913-8.

18. van Son JAM, Mohan Reddy V, Silverman NH, Hanley FL. Regression of tricuspid regurgitation after two-stage arterial switch operation for failing systemic right ventricle after atrial inversion operation. J Thorac Cardiovasc Surg. 1996;111:42-7.

19. Langley S, Winlaw D, Stumper O, Dhillon R, Degiovanni J, Wright J, et al. Midterm results after restoration of the morphologically left ventricle to the systemic circulation in patients with congenitally corrected transposition of the great arteries. J Thorac Cardiovasc Surg. 2003;125:1229-40.

20. Dubin AM, Janousek J, Rhee E, Strieper MJ, Cecchin F, Law IH, et al. Resynchronization therapy in pediatric and congenital heart disease patients: an international multicenter study. J Am Coll Cardiol. 2005;46:2277-83.

21. Kiesewetter C, Michael K, Morgan J, Veldtman G. Left ventricular dysfunction after cardiac resynchronization therapy in congenital heart disease patients with a failing systemic right ventricle. Pacing Clin Electrophysiol. 2008;31:159-62.

22. Hechter SJ, Webb G, Fredriksen PM, Benson L, Merchant N, Freeman M, et al Cardiopulmonary exercise performance in adult survivors of the Mustard procedure. Cardiol Young. 2001;11:407-14.

23. Fredriksen PM, Chen A, Veldtman G, Hechter S, Therrien J, Webb G. Exercise capacity in adult patients with congenitally corrected transposition of the great arteries. Heart. 2001;85:191-5.

24. Diller GP, Dimopoulos K, Okonko D, Uebing A, Broberg CS, Babu-Narayan S, et al. Heart rate response during exercise predicts survival in adults with congenital heart disease. J Am Coll Cardiol. 2006;48:1250-6.

25. Diller GP, Dimopoulos K, Okonko D, Li W, Babu-Narayan SV, Broberg CS, et al Exercise intolerance in adult congenital heart disease: comparative severity, correlates, and prognostic implication. Circulation. 2005;112:828-35.

26. Diller GP, Okonko DO, Uebing A, Dimopoulos K, Bayne S, Sutton R, et al. Impaired heart rate response to exercise in adult patients with a systemic right ventricle or univentricular circulation: prevalence, relation to exercise, and potential therapeutic implications. Int J Cardiol. 2009;134:59-66.

27. Khairy P, Landzberg M, Lambert J, O'Donnell C. Long-term outcomes after the atrial switch for surgical correction of transposition: a meta-analysis comparing the Mustard and Senning procedures. Cardiol Young. 2004;14:284-92.

28. Devaney EJ, Charpie JR, Ohye RG, Bove EL. Combined arterial switch and Senning operation for congenitally corrected transposition of the great arteries: patient selection and intermediate results. J Thorac Cardiovasc Surg. 2003;125:500-7.

29. Baumgartner H, Bonhoeffer P, De Groot NM, de Haan F, Deanfield JE, Galie N, et al. ESC Guidelines for the management of grown-up congenital heart disease (new version 2010). Eur Heart J. 2010;31:2915-57.

30. Sarkar D, Bull C, Yates R, Wright D, Cullen S, Gewillig M, et al. Comparison of long-term outcomes of atrial repair of simple transposition with implications for a late arterial switch strategy. Circulation. 1999;100(S2):176-81.

31. Wilson NJ, Clarkson PM, Barrat-Boyes BG, Calder AL, Whitlock RML, Easthope RN, et al. Long-term outcome after the Mustard repair for simple transposition of the great arteries. J Am Coll Cardiol. 1998;32:758-65.

32. Hraska V, Duncan BW, Mayer J, Freed M, del Nido P, Jonas R. Long-term outcome of surgically treated patients with corrected transposition of the great arteries. J Thorac Cardiovasc Surg. 2005;129:182-91.

33. Yeh T, Connelly MS, Coles JG, Webb GD, McLaughlin PR, Freedom RM, et al Atrioventricular discordance: results of repair in 127 patients. J Thorac Cardiovasc Surg. 1999;117:1190-203.

\section{Discussion}

Dr Shunji Sano (Okayama, Japan). There is always debate on whether the morphologic RV supports the systemic circulation for the patient's entire life or not. The American College of 
Cardiology/American Heart Association guidelines show that ventricular dysfunction seems to be related to systemic AV valve regurgitation. In the absence of associated congenital anomalies, primary RV failure is uncommon. Abnormality of the systemic AV valve is Ebstein-like malformation in $90 \%$ of the patients. In your series in the adult group, only 4 patients had Ebstein's. From your data, mortality is low with survival of $90 \%$ for TGA-atrial switch and $84 \%$ for ccTGA. However, cumulative mortality at 40 years from birth is $68 \%$ for TGA-atrial switch and $67 \%$ for ccTGA. This means most of the deaths in these patients occur in the pediatric age, and in the patients who survived to adult age, mortality is low with good RV function.

Do you have any data of TR and RV impairment of ccTGA in the pediatric age population, and what was the reason of death of these patients after TGA-atrial switch and ccTGA in the pediatric age population?

Dr Dobson. The main aim of this study was to look at outcomes in the adult patients who were cared for by the adult congenital heart disease service. In terms of causes of death in the pediatric population, we didn't assess this in detail. Furthermore, I have limited data regarding the severity of TR and systemic RV impairment as estimated from echocardiography or MRI in patients before the age of 18 years.

However, one can make some deductions. A significant number of the pediatric deaths occurred in association with the initial repair and early postoperative course, and most of these were in the late 1970 s or early 1980s. SRV failure also was a significant problem: Five patients in the pediatric population subsequently went on to have a successful double switch procedure, and 1 patient required cardiac transplantation after unsuccessful PA banding. The other cause of mortality in the pediatric patients was sudden cardiac death. This raises the question of how to prevent deaths due to SRV failure.

We know that as patients become older it is difficult to train the morphologic LV in preparation for an anatomic repair. Therefore, patients should be prepared for this at a young age, really as soon as it has become evident that they have significant TR or significant SRV failure. Professor Vouhé in Paris has published some fascinating work on applying a prophylactic PA band to all patients from birth with ccTGA. The reason behind this is to maintain physiologic training of the LV and, in theory, to be able to offer anatomic repair to all patients with ccTGA should they require it.

The key role of any research in this group is to try and identify a strategy that promptly identifies and intervenes in those patients at high risk of SRV failure, while at the same time recognizing that there are other patients who will do well with a more conservative approach.

Dr Sano. Your freedom from arrhythmia at 40 years was 0.51 for TGA-atrial switch and 0.93 for ccTGA. There is a discrepancy between TGA-atrial switch and ccTGA. Most of the arrhythmia in those with TGA-atrial switch was atrial tachyarrhythmia, and most of your atrial switch procedures were Mustard. Therefore, the reason of the arrhythmia is due to late complication of Mustard rather than RV dysfunction. Is the rate of arrhythmia the same in the Senning and Mustard groups?

Dr Dobson. The key thing is that the Senning group was smaller. I don't have the exact figures at hand, but I will find it for you later. If one looks at the absolute values, certainly Mustard cases accounted for most of the burden of tachyarrhythmia in the TGA-atrial switch cohort. Of the 21 patients in the atrial switch cohort with documented tachyarrhythmia, only 2 underwent Senning repair; the rest underwent Mustard. However, the a smaller number of patients underwent Senning, accounting for only one fifth of the atrial switch cases, and subsequent analysis demonstrated that there was no statistically significant difference in freedom from tachyarrhythmia between the 2 groups, with a $P$ value of .892 as estimated by the log-rank test: this data set is therefore underpowered in this respect.

However, when one compares freedom from tachyarrhythmia between the TGA-atrial switch cohort and the ccTGA cohort you are absolutely correct, there were higher rates of arrhythmia in TGA-atrial switch cases compared with ccTGA cases. My own feeling is that this reflects the extensive atrial scar tissue that has occurred as a result of the initial surgery, leading to a propensity for atrial macro-reentrant tachycardia.

Dr Sano. So that means if you perform a Senning operation, most of these arrhythmias will be avoided. Recent reports from many centers show a 20-year survival of more than $70 \%$ to $80 \%$ after the double switch, and the Fontan operation is now adopted in many cases rather than complex intracardiac repair, with a 10to 20 -year survival of $70 \%$ to $90 \%$, and the reintervention after Fontan is low.

We recently reported our results of ccTGA. Although the mean follow-up is only 10 years, in a double switch with the Senning arterial switch group, there was no mortality. In the Senning-Rastelli group, we measured the length between interventricular septum and aorta, and all early and late mortality came from the group with a long distance between the interventricular septum and aorta. There was no mortality in the patients with the short distance. Therefore, we do a Fontan operation in the long distance group and a double switch in the short distance group. I hope the long-term survival will improve using different techniques in individual patients.

Dr John Foker (Minneapolis, Minn). This is a valuable study, because there are a number of these patients. I did 50 atrial baffle procedures (modified Shumacker) for simple transposition. They all left the hospital, 2 or 3 died later suddenly, but many of them are doing well, including 1 woman who recently gave birth to a child with TGA.

My question concerns the RV dysfunction. These patients underwent operation at a time when myocardial protection was rudimentary at best and was, in essence, clamp and go, with the RV out under the hot lights. Do you think the RV dysfunction, when you see it, could be due mostly to this poor myocardial protection rather than any intrinsic inability of the RV to serve as the systemic ventricle? If so, when you looked at these hearts, would you see subendocardial fibrosis in those that were failing?

Dr Dobson. One would expect that more primitive myocardial protection techniques would result in greater myocyte necrosis in the SRV and consequent impairment. However, it is uncertain whether this is permanent or there is potential for recovery. There are clearly many other factors that could contribute to the development of SRV failure, not least because we know that some patients with isolated ccTGA who have never proceeded to surgery sometimes develop significant cardiac failure. To answer your question, one would need a larger study population. One could then compare outcomes between patients who had been repaired in the current 
era with all the advantages of modern techniques of myocardial protection and patients who had been repaired 20 or 30 years ago when such technology was less advanced. Multivariate analysis would then allow adjustment for confounding variables and provide insight into the effect of cardiopulmonary bypass in predicting those who will go on to develop late systemic RV impairment.

In answer to the second part of your question, subendocardial fibrosis is something that is currently difficult to assess by MRI. Even with late gadolinium enhancement, you are unlikely to be able to distinguish whether someone definitely has fibrosis. There is some interesting work looking at the use of MRI edema sequences for this purpose. It would be a fascinating study to try and objectively assess the amounts of fibrosis in SRVs and then compare these with the era of surgical repair. But I don't have the data for that in this study. The other problem is that many of these patients require permanent pacing, which precludes assessment by MRI at least in the current era.

Dr Gerhard Ziemer (Chicago, Ill). I understand that you have to simplify your conclusions in a talk like this, but I have to make 2 remarks.
For atrial repair of TGA, you cannot really put patients with and without VSD into 1 group and give them a single incidence for arrhythmias. The same is true for RV function, because you may have a different cause of RV function impairment, either secondary to TR or preceding it. This relates to VSD closure or no VSD closure. So at least in your article you should discuss this.

My second point relates to you just comparing arrhythmia incidence for ccTGA with arrhythmias in normal transposition. But you only can compare them for their types of arrhythmias: Patients post-atrial switch for TGA mainly have atrial arrhythmias and patients post-ccTGA have sudden AV block with and without surgery. So there is really a different mechanism of late failure, but I understand the simplification in your presentation.

Dr Dobson. Thank you.

Dr Craig Smith (New York, NY). This study is a sobering reminder that when we are dealing with a population with such a long life expectancy, the duration of follow-up required to answer any of these questions is long, and I look forward to the 40-year follow-up. 